investment. It requires leadership, workforce and skill mix review, workforce flexibility and a dedicated team.

Disclosure of Interest None Declared.

\section{PTH-122 A RETROSPECTIVE STUDY TO COMPARE THE EFFECTIVENESS OF REFERRAL METHODS TO ALCOHOL SERVICES FOR SPECIALIST TREATMENT FROM AN ACUTE HOSPITAL FOLLOWING BRIEF INTERVENTION}

doi:10.1136/gutjnl-2013-304907.609

${ }^{1} \mathrm{M}$ Vardy, ${ }^{2} \mathrm{E}$ Day, ${ }^{2} \mathrm{~K}$ Webb, ${ }^{3} \mathrm{C}$ Russell, ${ }^{3,} \mathrm{P}$ Sudhakaran, ${ }^{3}$ Ahmad, ${ }^{4} \mathrm{~K}$ Cobain, ${ }^{3} \mathrm{D}$ Aldulaimi. 'Worcestershire Acute Hospitals NHS Trust, Worcestershire; ${ }^{2}$ Birmingham and Solilhull Mental Health Trust, University of Birmingham, Birmingham; ${ }^{3}$ Worcestershire Acute Hospitals NHS Trust, Redditch; " University of Birmingham, Birmingham, UK

Introduction Screening, brief intervention and referral to treatment (SBIRT) programmes have been advocated as having a preventive effect in non dependent drinkers and can provide a pathway to access specialist treatment for alcohol use disorders (AUD) for hospitalised patients who are contemplating changing their drinking behaviour. Little research into the effect of referral methods in hospitalised people treated for AUDs has been carried out.

Methods Patient data for 2007-2009 were retrospectively reviewed in order to compare two referral to treatment methods namely, referral to treatment by a specialist nurse (RTT group) or self referral supported by a specialist nurse (SSR). Attendances at offered appointments were compared to identify each referral methods efficacy in eliciting attendance at a community alcohol treatment service following a request for further treatment for AUD elicited during hospitalisation in an acute setting.

Results The sample size was 76; the most common reason for hospitalisation was deliberate overdose with alcohol (17.3\%) followed by fall or collapse with alcohol (11.8\%) Alcoholic Liver Disease with alcohol withdrawal (7.3\%).

Of 76 Patients referred to treatment by both methods, 36 were in the SSR group and 40 in the RTT group, no significant difference in response to referral modality between the RTT and SSR group was detected.

Conclusion This study found no evidence of a difference in effectiveness of referral methods. This suggests that both referral methods were as effective as each other in eliciting attendance at a specialist alcohol treatment service after an offer of treatment had been made during acute hospitalisation. Further studies, with a larger population, are required to validate this finding

Disclosure of Interest None Declared.

\section{PTH-123 THE EFFECTIVENESS OF AN ALCOHOL LIAISON NURSE SERVICE AT REDUCING FUTURE ALCOHOL RELATED ATTENDANCES TO A COUNTY'S ACCIDENT \& EMERGENCY DEPARTMENTS}

doi:10.1136/gutjnl-2013-304907.610

'E Davies, ${ }^{2} \mathrm{M}$ Vardy, ${ }^{1, *} \mathrm{~S}$ Prabhakaran, ${ }^{1} \mathrm{~A}$ Ahmad, ${ }^{3} \mathrm{~K}$ Cobain, 'D Aldulaimi. 'Worcestershire Acute Hospitals NHS Trust, Redditch; ${ }^{2}$ Worcestershire Acute Hospitals NHS Trust, Worcestershire; ${ }^{3}$ University of Birmingham, Birmingham, UK

Introduction Worcestershire Acute NHS Trust has an Alcohol Liaison Nurse Service (ALN) based in two Emergency Departments; this provides assessments including screening, brief interventions and referrals into treatment. They function during office hours only. We wanted to evaluate how effective these roles are in reducing the trend in future alcohol related attendances.

Methods Patients were identified by either non-specialist clinicians or the ALN, where alcohol had been a factor in their attendance at A\&E, Emergency Decisions Unit (EDU) or Medical Assessment Unit (MAU). They were seen by the ALN who delivered a Brief Intervention (BI).
Their attendances to $\mathrm{A}+\mathrm{E}$ were compared for the period 12 months before and after the brief intervention to identify whether their attendance patterns varied.

The comparison was carried out by visual audit of patient records on Patient First $\mathrm{A}+\mathrm{E}$ records system.

Results Since the inception of the ALN service, year on year the figures show a reduced number of re-attendance. Since the inception of the ALN service 1688 patients received a brief intervention, the number of attendances 12 months pre BI were 3814, with 2155 in the 12 months following BI. This shows a reduction of $43 \%$. Based on National Indicators on average, each alcohol related A\&E attendance costs $£ 80$ (NHS evidence ID:10/0021 2012), this suggests a Trust saving of $£ 132,720.00$ over a four year period.

Conclusion These results confirm the efficacy of BI delivered by an ALN service in district general hospital based emergency departments. As a result of these findings other departments within our Trust are developing identification of Alcohol use disorders and Brief Interventions.

Disclosure of Interest None Declared.

\section{PTH-124 ACTION LEARNING SETS TO SUPPORT SPECIALIST SCREENING PRACTITIONERS}

doi:10.1136/gutjnl-2013-304907.611

1.1, $\mathrm{V}$ Breen. 'Screening Division, Public Health UK, Bowel Screening UK, Pontyclun, UK

Introduction Bowel Screening Wales (BSW) have undertaken a pilot to provide evidence which will consider the benefits of Action Learning Sets to Support Specialist Screening Practitioners.

Methods Action Learning Sets (ALS) are a powerful problem-solving process widely used in nursing and other organisations to help staff develop their own skills in resolving workplace issues by using enhanced communication in a group setting. It can help build teams, support individuals, develop self awareness, promote professional development and improve leadership skills. Allocating time for one-to-one meetings for clinical supervision can be difficult to maintain. ALS could be developed to enable SSP peer-group learning. A pilot will commence in one LAC in January 2013 and will create a mechanism for setting up action learning, enabling discussion of the options and the practicalities of setting up ALS. A Bowel Screening Wales, Regional Nurse would take on the initial facilitator role. This would help to ensure progress is maintained and to encourage and shape ALS, with a view totraining up internal facilitators for future sets in other LACs. The ALS would become self facilitating but this would only be done once the SSP's are experienced in the methodology. Those involved in the pilot would need to agree how the ALS pilot will be evaluated, one possibility would be to ask members to write a reflective account of their experience of participating and how it influenced their practise and professional development.

Results The feedback from the results will be considered and the process consent process modified accordingly. The results of the pilot will help BSW focus on finding out how ALS could enable SSP peer-group learning, development and support providing peer supervision, identifying strategies for leading service developments and providing a focus for problem solving and reflection workplace issues. Also needing consideration is how the pilot, if successful, could be conveyed to other SSP's working within Bowel Screening Wales, SSP's working within other UK Bowel Screening Programmes and other Specialist Nurses working within the symptomatic service.

Conclusion ALS for SSP's would ensure continuous professional development and could represent an empowering approach for SSP's advanced practise, helping them to develop their own practical solutions to workplace problems and issues. ALS is a dynamic and evolving group process. The approach would require commitment but ALS is a relatively straight forward way of 
improving individual SSP and team working. It aims to be of benefit to the organisation and the individual SSP.

Disclosure of Interest None Declared.

\section{Service development}

\section{PTH-125 A NEW LOWER GASTROINTESTINAL 2-WEEK WAIT 'DIRECT TO TEST' PATHWAY RESULTS IN EARLIER DIAGNOSIS OF CANCER}

doi:10.1136/gutjnl-2013-304907.612

1,*A Humphries, ${ }^{1} \mathrm{~J}$ Clarke, ${ }^{2} \mathrm{G}$ Bhatnagar, ${ }^{2} \mathrm{~J}$ Jenkins, ${ }^{2} \mathrm{D}$ Burling, ${ }^{2,3} \mathrm{~S}$ Thomas-Gibson. ${ }^{1} \mathrm{Im}$ perial College Healthcare NHS Trust; ${ }^{2}$ St Mark's Hospital; 3 Imperial College, London, UK

Introduction As part of the National Awareness and Early Diagnosis Initiative (NAEDI) ${ }^{1}$, a symptom awareness campaign for bowel cancer was piloted in the UK in 2010 and 2011. The results suggested that referrals from primary care would increase by up to $30 \%$ when extended nationally from $30^{\text {th }}$ January 2012 . As a result, a new two-week wait (2WW) pathway for suspected colorectal cancer was developed at North West London Hospitals NHS Trust that aimed to decrease the projected burden on colonoscopy and triage the majority of patients direct to an appropriate diagnostic test - 'direct-to-test' (DTT), in order to reduce the time and number of appointments before cancer is diagnosed. Previously, patients were triaged to either an out-patient appointment or flexible sigmoidoscopy (FS); the new DTT pathway triaged patients to either FS, colonoscopy, CT colonography (CTC) or an out-patient appointment based on age and symptomatology.

Methods Outcome data for all patients referred via the old pathway for the months of May 2011 and January 2012, and those seen via the new DTT pathway for March 2012 and May 2012 were audited to assess clinical effectiveness.

Results There was a 33\% increase in patients referred with suspected lower GI cancer following the NAEDI campaign, and this was sustained to May 2012. On the previous pathway the majority $(60 \%)$ of patients were seen first in out-patients before a diagnostic test was requested, whereas over $85 \%$ of patients proceeded DTT with the new pathway. There was no significant difference in the proportion of colonic and extra-colonic cancers diagnosed between the two pathways, however more patients were diagnosed with colorectal polyps using the new pathway. Patients with cancer referred via the DTT pathway had a significantly reduced median time to diagnosis compared to those on the old pathway (10 days vs 15 days respectively, $\mathrm{p}<0.05$ ), and patients seen via the new DTT pathway had significantly fewer hospital appointments compared to those seen on the old pathway (1.9 vs 2.8 respectively, $p<0.0001)$. Conclusion Symptom awareness campaigns increase demand for colorectal diagnostic services. We have demonstrated that a new DTT 2WW pathway for suspected colorectal cancer reduces the time to diagnosis of colonic neoplasia, whilst increasing outpatient capacity by involving fewer hospital attendances. Use of CT colonography for older patients decreases the burden on diagnostic colonoscopy, creating more targeted therapeutic endoscopy capacity.

Disclosure of Interest None Declared.

\section{REFERENCE}

1. Cancer Reform Strategy; Department of Health, December 2007.

\section{PTH-126 A FUNCTIONAL MODEL OF OF A 'SEVEN DAY ACUTE GASTROENTEROLOGY SERVICE': LOOKING BEYOND OUT-OF-HOURS ENDOSCOPY}

doi:10.1136/gutjnl-2013-304907.613

1."A Jawhari, 'L Meran, ${ }^{2} \mathrm{~A}$ McCarthy, ${ }^{3} \mathrm{~N}$ Lewis, ${ }^{4} \mathrm{G}$ Aithal. ${ }^{1}$ Gastroenterology, NIHR Biomedical Research Unit in Gastrointestinal and Liver Diseases at the Nottingham University Hospitals and University of Nottingham; ${ }^{2}$ Gastroenterology, Nottingham University Hospitals; ${ }^{3}$ NIHR Biomedical Research Unit in Gastrointestinal and Liver Diseases at the
Nottingham University Hospitals and University of Nottingham, Nottingham, UK; ${ }^{4} \mathrm{Hepa}-$ tology, NIHR Biomedical Research Unit in Gastrointestinal and Liver Diseases at the Nottingham University Hospitals and University of Nottingham, Nottingham, UK

Introduction Early involvement and management by specialists has been shown to have a favourable impact on outcomes in a number of acute medical conditions. Increased patient mortality at weekends has also been attributed to limited access to specialist services. While an increasing number of hospitals provide an out-ofhours service for upper gastrointestinal bleeding, examples of a comprehensive acute Gastroenterology services are infrequent.

Methods In January 2007, we established an acute gastroenterology service to provide consultant-lead assessment and management for all patients identified through acute servieces with symptoms related to gastrointestinal and hepato-pancreatico-biliary conditions. The consultant of the week lead and delivered the service supported by a registrar and a dedicated inpatient endoscopy team, free from any commitment to elective services. Inpatient care was supported by daily consultant led ward rounds. We achieved the 'critical mass' to deliver this service by consolidating all inpatient work on on site.

Results Mean LOS of all patients discharged with a gastroenterology HRG, from the specialist gastroenterology ward was 7.6 days, and from non-specialist medical beds was 9.6 days. Overall the specialist gastroenterology ward provided care for 1.8 times more patients compared with other Medical wards of the same size at NUH. Actual mean LOS (for the period of 2011-2012) was significantly shorter than the 'expected' LOS, and than mean peer LOS for 4 main diagnostic categories (table) with no significant increase in readmission rates. Discharge rates were maintained at the same level during the weekend (mean 4 discharges per weekday and on Saturday, with a peak of 6 discharges on Fridays and a dip to a mean of 3 discharges on Sunday.

\section{Abstract PTH-126 Table 1}

\begin{tabular}{lcccc}
\hline Diagnosis & $\begin{array}{c}\text { NUH actual LOS } \\
\text { (days) }\end{array}$ & $\begin{array}{c}\text { NUH expected } \\
\text { LOS (days) }\end{array}$ & $\begin{array}{c}\text { Peer mean LOS } \\
\text { (days) }\end{array}$ & \% difference \\
\hline GI Bleed & 4.2 & 5.8 & 5.8 & $-27 \%$ \\
Acute colitis & 6.3 & 7.2 & 7.6 & $-15 \%$ \\
ALD & 6.6 & 11.7 & 11.5 & $-43 \%$ \\
Other liver disease & 5.8 & 8.7 & 6.9 & $-15 \%$ \\
\hline
\end{tabular}

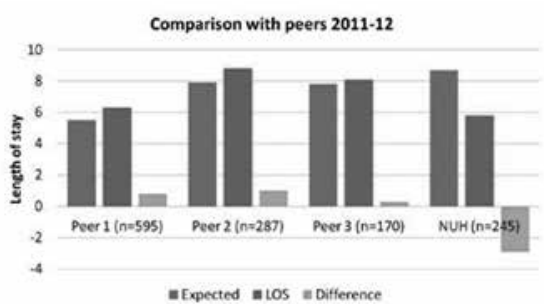

Abstract PTH-126 Figure 1

Conclusion Specialist led care can be provided to all patients with acute gastrointestinal and hepato-pancreatico-biliary conditions. A functional 7-day 'acute gastroenterology' can be sustained to provide high quality and intensity of care with favourable outcomes. Disclosure of Interest None Declared.

\section{PTH-127 APPROPRIATENESS OF USE OF MRCP (MAGNETIC RESONANCE CHOLANGIO-PANCREATICGRAPHY) IN PATIENTS WITH SUSPECTED CBD STONES - A DISTRICT GENERAL HOSPITAL EXPERIENCE}

doi:10.1136/gutjnl-2013-304907.614

\footnotetext{
1.1,*A Uppal, ${ }^{2} \mathrm{~S}$ Latif, ${ }^{2} \mathrm{G}$ Sheiybani, ${ }^{3} \mathrm{~S}$ Shetty. ${ }^{1}$ Gastroenterology; ${ }^{2} \mathrm{NHS}$, Birmingham, ${ }^{3}$ Gastroenterology, Dudley Group of Hospitals, Dudley, UK
} 